Cardiology 1980, 66:I-VI

\title{
Contents Vol. 66, 1980
}

\section{No. 1}

Original Paper

Aortic and Brachial Pulse Wave Contour and Timing in Aortic Valve Disease

Hasegawa, M. and Rodbard, S. $\dagger \quad 1$

Noninvasive Visualization of Right Coronary Artery Aneurysms

Karlsberg, R.P.; Eisenstein, I.; Aronow, W.S.; Edelstein, J., and

Chandraratna, P.A.N 18

Hemodynamic Effects of Combined Treatment with Lignocaine, Procainamide and Practolol in Acute Myocardial Infarction

Nordlander, R. and Nyquist, O.

Comparison of Rest/Exercise ECG, Thallium-201 Scans and Radionuclide Angiography in

Patients with Suspected Coronary Artery Disease

Pfisterer, M.E.; Williams, R.J.; Gordon, D.G.; Swanson, S.M.; Battler, A.;

Ceretto,W.J.; Ashburn,W.L., and Froelicher, V.F. 43

Exercise Testing and Rehabilitation in Cardiology

Blood Pressure Responses to Bicycle Exercise Testing in Apparently Healthy Middle-Aged Men Erikssen, J.; Jervell, J., and Forfang, K 56

Book Review 64

Contents

IV

No. 2

Original Paper

QRS Waveform of Ventricular Extrasystoles and Their Differentiation from Aberrant

Conduction

Talbot, S.;Kilpatrick, D., and Weeks, B 65

Sex Differences in Cardiac Function of a Group of Young Adults

Harrison, W.K. and Smith, J.E 74

Correlation of 99mTc-Pyrophosphate Myocardial Accumulation with Left Ventricular Wall

Motion Abnormalities

Wisneski, J.A.; Rollo, F.D., and Gertz, E.W 85

Duration of the Hypotensive Action of Nitroglycerin Ointment in Ambulatory Subjects Utilizing an Automatic Blood Pressure Recording Device

Chandraratna, P.A.N.; Chu, W.; Schneider, R., and SanPedro, S 102

Exercise Testing and Rehabilitation

Pilot Study Examining the Motivational Effects of Maximal Exercise Testing to Modify Risk

Factors and Health Habits

Bruce, R.A.; DeRouen, T.A., and Hossack, K.F 111

Exercise Capacity, Residual Abnormalities and Activity Habits following Total Correction for Tetralogy of Fallot 
Lambert, J.; Ferguson, R.J.; Gervais, A., and Gilbert, G

Book Review 132

No. 3

Original Paper

Protection of Ischemic Myocardium: Comparison of Effects of Propranolol, Bevantolol and N-

Dimethyl Propranolol on Infarct Size following Coronary Artery Occlusion in Anesthetized

Dogs

Warltier, D.C.; Gross, G.J.;Jesmok, G.J.; Brooks, H.L., and Hardman, H.F 133

Systolic Anterior Motion of the Mitral Valve with and without Asymmetric Septal Hypertrophy.

Role of Left Ventricular Posterior Wall Motion

Udoshi, M.; Shah, A.; Fisher, V.J., and Dolgin, M 147

Changes in Autonomic Nerve Activity during Acute Pericardial Tamponade

Castaner, A.;Kostreva, D.R., and Kampine, J.P 163

Clinical Usefulness of Computer Diagnosis in Automated Electrocardiography

Endou, K.; Miyahara, H., and Sato, T174

Book Reviews

190

Contents V

No. 4

Original Paper

Noninvasive Assessment of Left Ventricular Effects of Hydralazine in Heart Failure

Deglin, S.M.; Jain, A.C., and Harris, W.S 193

Prenylamine-Induced Ventricular Arrhythmias and Syncopal Attacks with

Q-T Prolongation

Report of a Case and Comment on Therapeutic Use of Lignocaine

Riccioni, N.; Bartolomei, C, and Soldani, S 199

Prevention

An Approach to Preventive Cardiology in Asymptomatic, Sedentary Adults

Dressendorfer, R.H. and Amsterdam, E.A 204

Exercise Testing and Rehabilitation

An Introduction to the Applications, Methodology and Interpretation of Exercise

Electrocardiography

Froelicher, V.F 223

Toward Improved Interpretation of the Exercise Test

Amsterdam, E.A.; Dressendorfer, R.H., and Mason, D.T. (Davis,

Calif./Sacramento, Calif.) 236

Clinical, Angiographic and Hemodynamic Characteristics of Patients with a Strongly Positive

Exercise Test

Williams, D.O. and Most, A.S 241

Book Review 250

Books Received at the Editorial Office

Author Index 252

Subject Index 253

Supplement I

Current Concepts in the Therapy of Hypertension with Beta-Blockers 
Sandoz Symposium on the occasion of the 7th Asian-Pacific Congress of Cardiology, Bangkok, November 25-30, 1979

Editor: S. Chaithiraphan, Bangkok

Contents

VI

Supplement II

Simposio Interamericano Prazosin en Hipertensión Arterial e Insuficiencia Cardiaca

Acapulco, Septiembie 2-3, 1979

Editores: Asa Zatz y J. Rafael Blengio 